\title{
Species differences in the regulation of cumulus expansion by an oocyte-secreted factor(s)
}

\author{
B. C. Vanderhyden \\ Department of Medicine, University of Ottawa, 451 Smyth Road, Ottawa, Ontario, \\ Canada K1H $8 \mathrm{M} 5$
}

\begin{abstract}
The expansion of the mouse cumulus oophorus in vitro in response to $\mathrm{FSH}$ is dependent upon the presence of an enabling factor secreted by the oocyte. The purpose of this study was to determine whether the expansion of cumulus cells from rats and pigs were similarly dependent upon an oocyte-secreted enabling factor. Mouse and rat oocyte-cumulus cell complexes were isolated from pregnant mares' serum gonadotrophin (PMSG)-stimulated animals; pig oocyte-cumulus cell complexes with the attached piece of mural granulosa were obtained from either prepubertal gilts or cyclic sows. FSH $\left(25-1000 \mathrm{ng} \mathrm{ml}^{-1}\right)$ or dibutyryl cyclic adenosine monophosphate ( $\mathrm{dbcAMP} ; 0.05-2 \mathrm{mmol}^{-1}$ ) induced a dose-dependent expansion of the oocyte-cumulus complexes from rats and pigs. The hypothesis that the oocyte plays a role in the regulation of cumulus expansion was tested by microsurgically removing oocytes from oocyte-cumulus complexes and the oocytectomized complexes were tested for their ability to undergo expansion in response to FSH. FSH did not induce cumulus expansion in oocytectomized mouse complexes; however, expansion occurred in rat and pig oocytectomized complexes. The pieces of mural granulosa, detached from the pig complexes, also expanded in response to FSH stimulation. Rat and pig oocytectomized complexes were then held in culture for up to $48 \mathrm{~h}$ before stimulation by FSH. The degree of expansion in rat oocytectomized complexes decreased as the delay before FSH stimulation increased such that, with an $8 \mathrm{~h}$ delay, oocytectomized complexes did not expand. Pig oocytectomized complexes expanded fully even with a $32 \mathrm{~h}$ delay before $\mathrm{FSH}$ stimulation, and in response to dbcAMP or epidermal growth factor (EGF). Finally, when rat or mouse oocytectomized complexes were cocultured with germinal vesicle-stage mouse, rat or pig oocytes, FSH stimulated expansion by all oocytectomized complexes. These results indicate that a factor(s) secreted by mouse and rat oocytes is necessary for the cumulus cells to undergo expansion in response to FSH, EGF or dbcAMP. Pig oocytes can secrete a cumulus expansion-enabling factor, but expansion of pig complexes does not depend upon this factor.
\end{abstract}

\section{Introduction}

During the development of the ovarian follicle, the granulosa cells proliferate to form a multilayered epithelium around the growing oocyte. Towards the end of the growth phase, the granulosa cells differentiate into two subpopulations organized as pseudostratified epithelia: mural granulosa cells in contact with the basal lamina that circumscribes the follicle, and cumulus granulosa cells enclosing the oocyte and coupled by gap junctions to both the oocyte and the surrounding mural granulosa cells (Anderson and Albertini, 1976; Heller and Schultz, 1980; Moor et al., 1980). These two cell types differ in their distribution of receptors (Amsterdam et al., 1975; Bortolussi et al., 1979; Lawrence et al., 1980) and their steroidogenic capabilities (Hillensjo et al., 1981; Zoller and Weisz, 1978, 1979). In addition, these cells show a dramatic difference in their response to the preovulatory surge of gonadotrophins. Gonadotrophins

Received 30 June 1992. stimulate cumulus granulosa cells to produce and secrete hyaluronic acid that disperses the cumulus cells, a process called expansion or mucification (Dekel and Kraicer, 1978; Eppig, 1979a; Salustri et al., 1989). Mural granulosa cells do not undergo expansion but become luteal cells.

Recent studies have demonstrated that the proliferation, differentiation and function of mouse granulosa cells are dependent upon the oocyte (Buccione et al., 1990; Salustri et al., 1990; Vanderhyden et al., 1990, 1992). A microsurgical procedure whereby the oocyte can be removed from the oocytegranulosa cell complex (oocytectomy) was used and continual contact of the granulosa cells with the oocyte was found to be necessary for the differentiation of granulosa cells into functional cumulus cells (Vanderhyden et al., 1990). Furthermore, soluble factors secreted by mouse oocytes promoted granulosa cell proliferation and helped to maintain the structural organization of the follicle (Vanderhyden et al., 1990, 1992). A specific role of the oocyte in the regulation of cumulus cell function in vitro has also been demonstrated (Buccione et al., 1990; Salustri 
et al., 1990; Vanderhyden et al., 1990). Cumulus expansion is induced in vitro by FSH (Thibault, 1972; Dekel and Kraicer, 1978; Eppig, 1979a, b; Hillensjo and Channing, 1980; Ball et al., 1985; Salustri et al., 1989), via a mechanism that appears to be mediated by cAMP (Dekel and Kraicer, 1978; Eppig 1979b). Epidermal growth factor (EGF) is also a potent stimulator of cumulus expansion (Downs et al., 1988). However, separation of the oocytes from the cumulus cells impaired the ability of the cumulus cells to synthesize hyaluronic acid and undergo cumulus expansion in vitro, indicating that mouse oocytes secrete a specific, developmentally regulated cumulus expansion-enabling factor that allows cumulus cells to undergo expansion in response to FSH, 8-bromo-cAMP or EGF (Buccione et al., 1990; Salustri ef al., 1990; Vanderhyden et al., 1990). The action of this oocyte-secreted factor occurs downstream from the FSHinduced increase in intracellular cAMP (Buccione et al., 1990).

A recent study using oocytectomized pig complexes has determined that, in contrast to mouse cumulus expansion, the expansion of pig oocyte-cumulus complexes in vitro is not dependent upon the oocyte (Procházka et al., 1991). This observation suggests that pig oocytes do not secrete a cumulus expansion-enabling factor and, therefore, that there are differences among species in the factors that regulate cumulus expansion. In this study, these possibilities were investigated by comparing the ability of factors secreted by mouse, rat and pig oocytes to enable cumulus expansion in response to FSH, dibutyryl cAMP (dbcAMP) and EGF. The specific aims of the study were ( 1 ) to determine whether the expansion of rat oocyte-cumulus cell complexes is dependent upon a cumulus expansion-enabling factor secreted by the oocyte, (2) to determine whether pig and rat oocytes secrete a cumulus expansionenabling factor, and (3) to determine the species specificity of the activity of cumulus expansion-enabling factors secreted by mouse, rat and pig oocytes.

\section{Materials and Methods}

\section{Isolation of oocyte-cumulus cell complexes}

Mouse ovaries were obtained from 22- to 24-day-old BALB/c mice injected $44 \mathrm{~h}$ previously with 5 iu pregnant mares' serum gonadotrophin (PMSG). Sprague-Dawley rats (26- to 28-dayold) primed with 7.5 iu PMSG provided rat ovaries. With these treatments, the ovaries yield 40-50 oocyte cumulus cell complexes per animal. Mouse and rat oocyte-cumulus cell complexes were isolated by puncturing antral follicles with 25 -gauge needles in Waymouth MB 752/1 (WAY) containing $75 \mathrm{mg}$ penicillin-G $\mathrm{l}^{-1}, 50 \mathrm{mg}$ streptomycin sulfate $\mathrm{I}^{-1}$ and $25 \mathrm{mg}$ sodium pyruvate $\mathrm{I}^{-1}$ (all from Sigma Chemical Co., St Louis, MO). The culture medium was supplemented with $5 \%$ fetal bovine serum (FBS; Hyclone Laboratories, Inc., Logan, UT) and also contained $0.1 \mathrm{mmol} 3$-isobutyl-1-methylxanthine $\mathrm{I}^{-1}$ (IBMX; Aldrich Chemical Co., Milwaukee, WI) to inhibit meiotic maturation of the oocytes. After isolation, the complexes were washed three times in fresh medium.

Pig ovaries were obtained from prepubertal Landrace gilts (5-6 months old) or cyclic sows ( 2 years old) from a local abattoir. Ovaries were transported on ice in Dulbecco's phosphate-buffered saline supplemented with $5 \%$ FBS and $0.1 \mathrm{mmol}^{\mathrm{IBMX} \mathrm{l}^{-1} \text { and }}$
$1.25 \mu \mathrm{g}$ fungizone $\mathrm{ml}^{-1}$ (Gibco Laboratories, Grand Island, NY). Within $45 \mathrm{~min}$, the ovaries were transferred into prewarmed WAY/FBS/IBMX. Each antral follicle $(2-6 \mathrm{~mm}$ in diameter) was opened and a piece of mural granulosa with the attached oocyte-cumulus cell complex was scraped from the wall of the follicle. The complexes were then washed three times in fresh medium. Although the attached pieces of mural granulosa varied in size, the differences had no effect on the response to the treatments given in this study. In addition to assessing the response to treatments qualitatively, as described below, quantitative measurements were made by estimating the area of each piece of mural granulosa before and after treatment. Since the responses of complexes from the antral follicles of prepubertal or cyclic pigs did not differ in these experiments, they were treated as one group.

\section{Oocytectomy}

Oocytes were removed microsurgically from the isolated complexes with the use of two Leitz micromanipulators and a Leitz Labovert inverted microscope using a technique described previously (Buccione et al., 1990; Vanderhyden et al., 1990). Briefly, each complex was held with the holding pipette. The lancing pipette was then pushed through the cumulus cells and the oocyte into the holding pipette. Upon withdrawal of the lancing pipette, the negative pressure in the holding pipette aspirated the oocyte, leaving the partially collapsed zona pellucida in situ. When released from the holding pipette, the oocytectomized complex returned to a normal spherical shape. The time required to oocytectomize a set of 30 complexes was approximately $15 \mathrm{~min}$

\section{Culture of intact and oocytectomized complexes}

Intact and oocytectomized complexes were transferred to drops of $25 \mu \mathrm{l}$ (mouse and rat) or $100 \mu \mathrm{l}$ (pig) WAY/FBS/IBMX that were covered with washed mineral oil in Falcon culture dishes (Becton Dickinson, Lincoln Park, NJ). Light mineral oil (Fisher Scientific, Fair Lawn, NJ), $200 \mathrm{ml}$, was equilibrated with $20 \mathrm{ml}$ WAY/FBS by stirring for 4 days, with one media change after 2 days. After allowing the media to settle, the equilibrated oil was sterilized by filtration through a $0.45 \mu \mathrm{m}$ filter. In all experiments FSH (NIADDK-oFSH-17; 25-1000 $\mathrm{ng} \mathrm{ml}^{-1}$ ), dbcAMP (Sigma; $0.05-2 \mathrm{mmol} \mathrm{l}^{-1}$ ) or EGF (from submaxillary glands, Boehringer-Mannheim, Laval, Quebec; $2 \mathrm{ng} \mathrm{ml}^{-1}$ ) was added to the drops of medium to stimulate cumulus expansion. The complexes were then cultured for up to $24 \mathrm{~h}$ for mouse and rat complexes and up to $48 \mathrm{~h}$ for pig complexes at $37^{\circ} \mathrm{C}$ in $5 \%$ $\mathrm{CO}_{2}: 5 \% \mathrm{O}_{2}: 90 \% \mathrm{~N}_{2}$, before being assessed for the degree of cumulus expansion.

\section{Delay of stimulation after oocytectomy}

Tissue culture plates (24 wells; Corning Glass Works, Corning, NY) were coated with $200 \mu \mathrm{l} 2 \%$ agarose (ultra pure grade, Bethesda Research Laboratories, Gaithersburg, MD) and equilibrated with WAY/FBS/IBMX. Intact and oocytectomized rat and pig complexes were prepared as described previously and transferred to the wells (20-50 complexes per well). The 
agarose coating prevented the complexes from adhering to the tissue culture plate. The complexes were cultured for $1-48 \mathrm{~h}$ before transfer to drops of WAY/FBS/IBMX under oil and treatment with FSH $\left(1 \mu \mathrm{g} \mathrm{ml}^{-1}\right), \mathrm{dbcAMP}\left(2 \mathrm{mmoll}^{-1}\right)$ or EGF $\left(2 \mathrm{ng} \mathrm{ml}^{-1}\right)$. Complexes were assessed for the degree of cumulus expansion after 24 (rat) or $32 \mathrm{~h}$ (pig); the times were determined in preliminary experiments to achieve the maximum degree of cumulus expansion.

\section{Coculture of oocytectomized complexes with denuded oocytes}

Denuded oocytes were prepared by repeated pipetting of mouse, rat or pig oocyte-cumulus cell complexes with a Pasteur pipette. Groups of 50 denuded germinal vesicle-stage oocytes were transferred to $25 \mu \mathrm{l}$ drops of WAY/FBS/IBMX under oil in Falcon culture dishes and cultured for $24 \mathrm{~h}$; oocyte-free drops were also prepared. The next day, intact and oocytectomized complexes from mice, rats or pigs were transferred, in groups of 12-25 in minimum volume, to the drops of unconditioned or oocyte-conditioned media. In some treatments, complexes were added to media conditioned by oocytes from the same species. In other treatments, complexes were added to drops of denuded oocytes from a different species. FSH $\left(1 \mu \mathrm{g} \mathrm{ml}^{-1}\right)$, dbcAMP $\left(2 \mathrm{mmol} \mathrm{l}^{-1}\right)$ or EGF $\left(2 \mathrm{ng} \mathrm{ml}^{-1}\right)$ was then added to the cultures and the degree of expansion was scored after the appropriate period of culture.

\section{Preliminary characterization of the enabling factor}

The biochemical nature of the cumulus expansion-enabling factor was investigated in experiments in which medium was conditioned with denuded pig oocytes (two oocytes per $\mu$ l) as described above and subjected to one of three treatments: (1) maintained at $65^{\circ} \mathrm{C}$ for $30 \mathrm{~min}$, (2) treated with proteinase $\mathrm{K}$ (Bethesda Research Laboratories; $100 \mu \mathrm{g} \mathrm{ml}^{-1}$ ) for $7 \mathrm{~h}$ at $55^{\circ} \mathrm{C}$, which was then inactivated with phenylmethylsulfonylfluoride (PMSF, Boehringer-Mannheim; $200 \mu \mathrm{g} \mathrm{ml}^{-1}$ ), or (3) addition of PMSF $\left(200 \mu \mathrm{g} \mathrm{ml}^{-1}\right)$. Because the first two treatments would inactivate the serum proteins, as well as any oocyte-secreted proteins, the original concentration of FBS $(5 \%)$ was restored to the conditioned media following these two treatments. Groups of 20 oocytectomized mouse complexes were transferred to $25 \mu \mathrm{l}$ drops of unconditioned media, untreated oocyte-conditioned media, or the media that had been treated after conditioning. FSH ( $1 \mu \mathrm{g} \mathrm{ml}^{-1}$ ) was added to the drops and the degree of expansion was assessed after 20-24 h of culture.

\section{Assessment of cumulus expansion}

At the end of the culture period, the complexes were assessed for expansion according to a subjective scoring system described by Vanderhyden et al. (1990). In this system the degree of expansion is ranked from +1 to $+4:+1$ indicates the minimum observable response, where cumulus cells have a glistening appearance and are not adhering to the dish; +4 indicates the maximum degree of expansion where all layers of cumulus cells, including the corona radiata, have expanded. A score of $\mathrm{O}$ indicates no expansion; the cells are adhering to the
Table 1. The effect of FSH and dibutyryl cAMP (dbcAMP) on the expansion of porcine and rat oocyte-cumulus cell complexes in vitro

\begin{tabular}{|c|c|c|}
\hline \multirow[b]{2}{*}{ Culture conditions } & \multicolumn{2}{|c|}{ Degree of expansion } \\
\hline & Rat $^{\mathrm{a}}$ & $\mathrm{Pig}^{\mathrm{b}}$ \\
\hline Control & 0 & 0 \\
\hline \multicolumn{3}{|l|}{$\mathrm{FSH}\left(\mathrm{ng} \mathrm{ml}^{-1}\right)$} \\
\hline 25 & +1 to +2 & +2 \\
\hline 50 & +3 & +2 to +3 \\
\hline 100 & +3 & +3 \\
\hline 250 & +3 to +4 & +4 \\
\hline 500 & +3 to +4 & +4 \\
\hline 1000 & +3 to +4 & +4 \\
\hline \multicolumn{3}{|l|}{$\mathrm{dbcAMP}\left(\mathrm{mmol} \mathrm{l}^{-1}\right)$} \\
\hline 0.05 & 0 & 0 \\
\hline 0.1 & 0 & 0 \\
\hline 0.5 & +1 & +2 to +3 \\
\hline 1.0 & +1 to +2 & +3 to +4 \\
\hline 1.5 & +2 to +3 & +4 \\
\hline 2.0 & +3 to +4 & +4 \\
\hline
\end{tabular}

${ }^{a} 60$ rat oocyte-cumulus cell complexes were assessed for each treatment in a total of three experiments.

'45 pig oocyte-cumulus cell complexes were assessed for each treatment in a total of three experiments.

dish and spreading away from the complex. To ensure that the cumulus expansion induced in these complexes is a result of hyaluronic acid-synthesizing activity, samples of intact and oocytectomized expanded complexes from all treatment groups were exposed to $200 \mathrm{U}$ Streptomyces hyaluronidase $\mathrm{ml}^{-1}$ (Sigma) and the dissociation of cumulus cells was monitored for $10 \mathrm{~min}$. Since Streptomyces hyaluronidase specifically degrades hyaluronic acid, cumulus cell dispersion in the presence of this enzyme indicates that hyaluronic acid is a component of the expanded complexes.

\section{Results}

\section{FSH and dbcAMP stimulation of rat and pig cumulus expansion}

FSH and dbcAMP induced expansion in rat and pig oocytecumulus complexes in a dose-dependent manner (Table 1). The degree of expansion achieved by more than $80 \%$ of the rat complexes was +3 to +4 when they were cultured in at least $250 \mathrm{ng} \mathrm{FSH} \mathrm{ml} \mathrm{m}^{-1}$ or $2.0 \mathrm{mmol}$ dbcAMP $\mathrm{l}^{-1}$ for $24 \mathrm{~h}$. Pig oocyte cumulus complexes underwent complete expansion $(+4)$ at similar concentrations of FSH or dbcAMP after $32 \mathrm{~h}$ of culture. Shorter periods of culture resulted in lesser degrees of expansion (data not shown). FSH-stimulated expansion of oocyte-cumulus complexes is shown (Fig. Ia, b (pig) and Fig. $2 a, b(r a t))$. The pieces of mural granulosa attached to pig complexes also expanded in response to stimulation by $\mathrm{FSH}$ $\left(1 \mu \mathrm{g} \mathrm{ml}^{-1}\right)$ or dbcAMP ( $2 \mathrm{mmol}^{-1}$ ), even when they were detached from the complexes before treatment with the hormone (Fig. 3). In response to FSH, the area of each piece of 

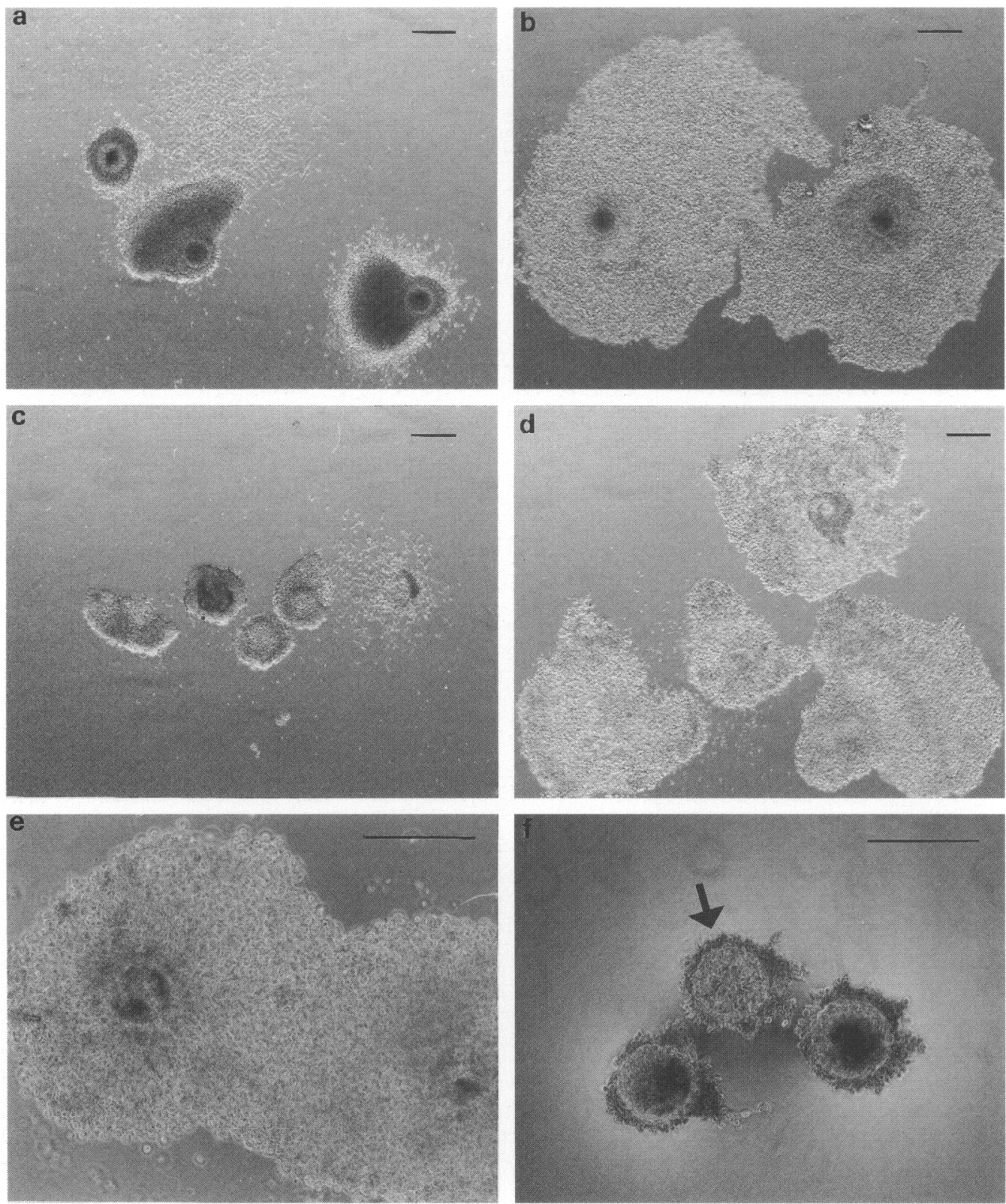

Fig. 1. Photomicrographs of (a, b) intact and (c, d, e) oocytectomized porcine oocyte-cumulus cell complexes with attached pieces of mural granulosa. Neither (a) intact nor (c) oocytectomized complexes expanded in the absence of gonadotrophic stimulation; however, both (b) intact and (d) oocytectomized complexes were expanded $32 \mathrm{~h}$ after stimulation by FSH $\left(1 \mu \mathrm{g} \mathrm{ml}^{-1}\right)$. (e) Expansion of oocytectomized complexes incubated for $24 \mathrm{~h}$ before treatment with FSH. (f) Hyaluronidase treatment of two intact complexes and one oocytectomized complex (indicated by the arrow) following expansion induced $24 \mathrm{~h}$ earlier by FSH. The pieces of mural granulosa and the cumulus cells, except the corona radiata, were dispersed within minutes. Scale bars $=250 \mu \mathrm{m}$.

mural granulosa increased at least tenfold $\left(0.181 \pm 0.008 \mathrm{~mm}^{2}\right.$ versus $\left.2.104 \pm 0.109 \mathrm{~mm}^{2}\right)$. FSH $\left(1 \mu \mathrm{g} \mathrm{ml}^{-1}\right)$ stimulated cumulus expansion of intact rat and pig complexes subjected to sham micromanipulation where the oocyte was penetrated but not aspirated or killed by the lancing pipette (data not shown). Expanded rat and pig complexes and the attached pieces of mural granulosa were dissociated within $4-5$ min by the addition of Streptomyces hyaluronidase. Hyaluronidase-treated pig complexes are shown (Fig. If).
Expansion of intact and oocytectomized mouse, rat and pig complexes

The dependence of FSH-induced cumulus expansion upon an oocyte-derived factor was investigated by removing oocytes from oocyte-cumulus complexes and stimulating the oocytectomized complexes with FSH. Whereas FSH induced +3 to +4 expansion in intact rat, pig (Table 2) and mouse (Table 3) oocyte-cumulus complexes, oocytectomized complexes of the different species 

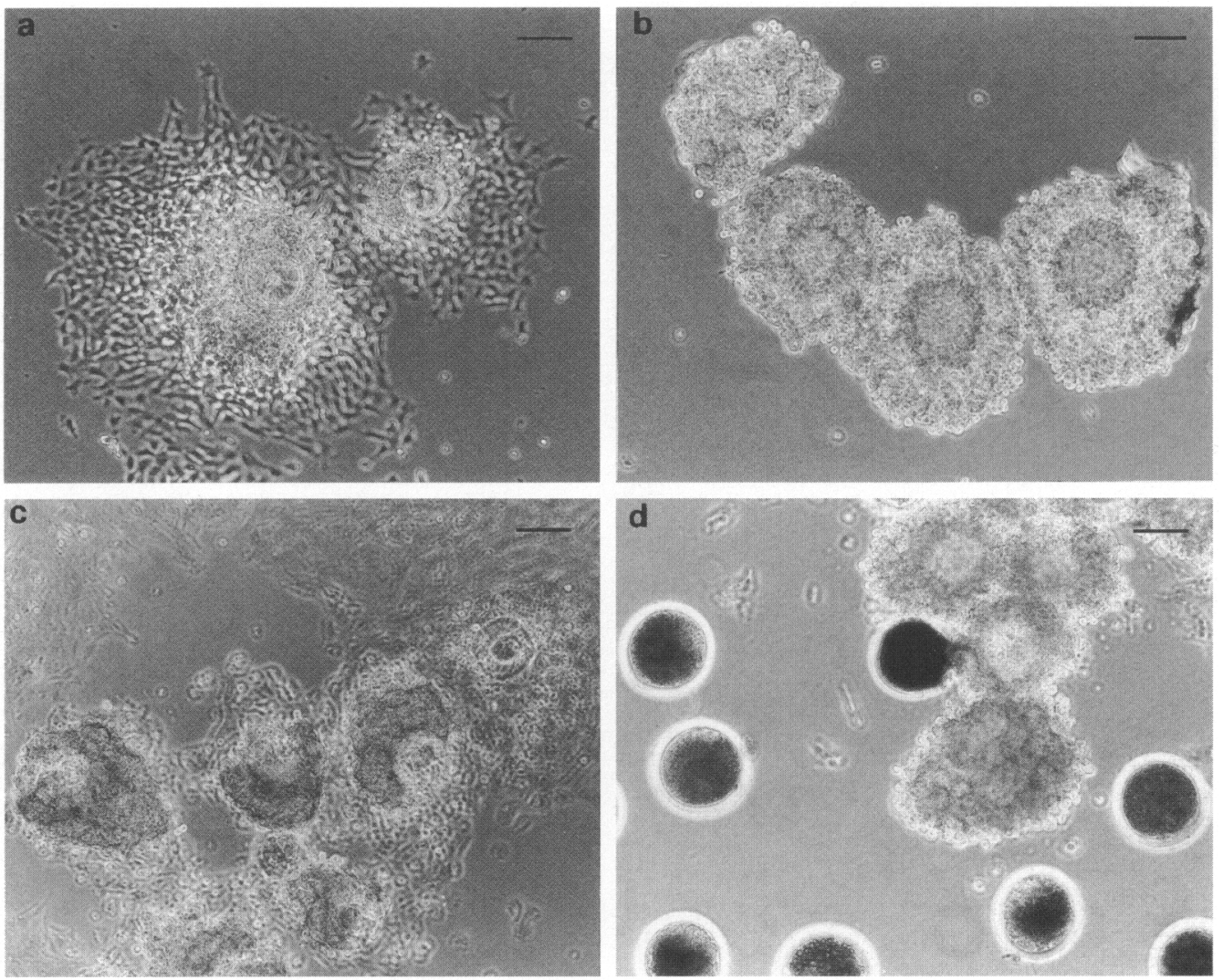

Fig. 2. Photomicrographs of (a, b) intact and (c, d) oocytectomized rat oocyte-cumulus cell complexes. Oocytectomized complexes were incubated for $5 \mathrm{~h}$ after oocytectomy before further treatment. Intact complexes were preincubated for an equivalent period. (a) In unstimulated, intact complexes, cumulus cells do not expand but, instead, adhere to the substrate and begin to migrate away from the oocyte. FSH ( $1 \mu \mathrm{g} \mathrm{ml}^{-1}$ ) induced the expansion of (b) intact but not (c) oocytectomized complexes. (d) Expansion of oocytectomized rat complexes cocultured overnight with porcine denuded oocytes $\left(2\right.$ oocytes $\left.\mu^{-1}\right)$ in the presence of FSH. Scale bars $=100 \mu \mathrm{m}$.

were more variable in their response to treatment. Oocytectomized mouse complexes failed to expand in response to FSH. Whereas FSH-stimulated oocytectomized rat complexes showed some expansion ( +2 ; Table 2$)$, the degree of expansion was less than that of intact complexes $(+3$ to +4 ; Table 2$)$. In contrast, pig complexes were unaffected by the removal of the oocyte, and exhibited expansion comparable to that of intact complexes $(+4$, Table 2).

\section{Delay of stimulation after oocytectomy}

The ability of rat and pig complexes to undergo FSH-induced cumulus expansion after oocytectomy suggests that expansion of the complexes of these species does not depend upon a factor produced by the oocyte. Alternatively, these results may be explained if the cumulus expansion-enabling factor from these species had a longer half-life than the mouse enabling factor, or if there was a delay in the loss of oocyte-induced biological effects on the cumulus cells.

To differentiate between these possibilities, oocytectomized rat and pig complexes were cultured for various periods after oocytectomy to ensure that the cumulus cells were not responding to previous stimulation by oocyte-secreted factors. Although intact rat complexes maintained their ability to expand in response to FSH over $24 \mathrm{~h}$, oocytectomized complexes demonstrated a decreasing ability to undergo expansion as the duration of culture after oocytectomy increased (Table 4 and Fig. 2c). By $4-8$ h after oocytectomy, the oocytectomized complexes had completely lost their ability to undergo FSH-stimulated cumulus expansion. In addition, the oocytectomized complexes were unable to expand in response to dbcAMP or EGF, stimuli that still induced cumulus expansion in intact complexes after a 5-6 h delay before stimulation (Table 5).

In contrast to the results observed in rat complexes, both intact and oocytectomized pig complexes maintained their ability to expand in response to FSH stimulation for up to $48 \mathrm{~h}$ (Table 4 and Fig. 1e). Similarly, the degree of expansion of oocytectomized complexes stimulated by dbcAMP or EGF was not affected when the stimulation was delayed by $24 \mathrm{~h}$ (Table 5).

\section{Coculture of oocytectomized complexes with denuded oocytes}

The decreased ability of rat oocytectomized complexes to undergo expansion when the FSH stimulation is delayed suggests that the cumulus cells do depend upon an oocytesecreted factor. Oocytectomized rat complexes were added to rat oocyte-conditioned medium, with or without $\mathrm{FSH}, \mathrm{dbcAMP}$ 


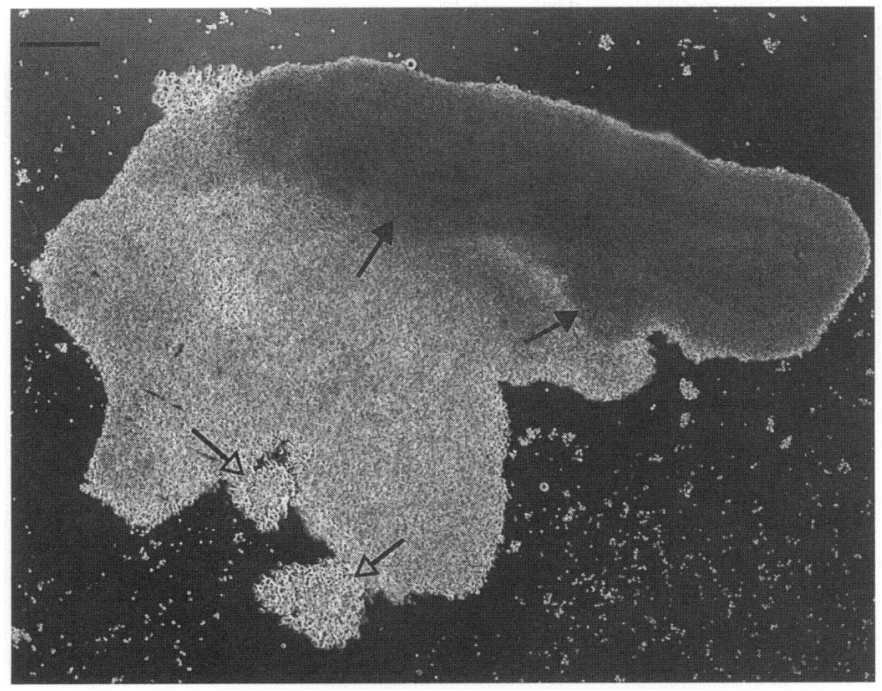

Fig. 3. Expansion of the piece of mural granulosa detached from a pig oocyte-cumulus cell complex. The piece of mural granulosa was incubated for $24 \mathrm{~h}$ before FSH $\left(1 \mu \mathrm{g} \mathrm{m}^{-1}\right)$ was added. Expansion was assessed after $32 \mathrm{~h}$. In this experiment, some intact rat oocyte-cumulus cell complexes (open arrows) were included in the culture to demonstrate cumulus expansion. Solid arrows indicate the boundary separating the cells of the piece of mural granulosa that undergo expansion from those that do not expand. Scale bar $=250 \mu \mathrm{m}$.

Table 2. Expansion of FSH-stimulated intact and oocytectomized complexes

\begin{tabular}{|c|c|c|c|}
\hline \multirow{2}{*}{$\begin{array}{l}\text { Culture } \\
\text { conditions }\end{array}$} & \multirow{2}{*}{$\begin{array}{l}\text { Type of } \\
\text { complex }\end{array}$} & \multicolumn{2}{|c|}{ Degree of expansion } \\
\hline & & $\operatorname{Rat}^{\mathrm{a}}$ & $\mathrm{Pig}^{\mathrm{b}}$ \\
\hline \multirow[t]{2}{*}{ Control } & Intact & 0 & 0 \\
\hline & Oocytectomized & 0 & 0 \\
\hline $\begin{array}{l}\mathrm{FSH} \\
\quad\left(1 \mathrm{\mu g} \mathrm{ml}^{-1}\right)\end{array}$ & $\begin{array}{l}\text { Intact } \\
\text { Oocytectomized }\end{array}$ & $\begin{array}{c}+3 \text { to }+4 \\
+2^{c}\end{array}$ & $\begin{array}{c}+4 \\
+3 \text { to }+4\end{array}$ \\
\hline$(1 \mu \mathrm{gm})$ & Nocytectomized & $+2^{2}$ & +3 to +4 \\
\hline
\end{tabular}

${ }^{\star} 135$ rat complexes were assessed for each treatment in a total of seven experiments.

'50 to 58 pig complexes were assessed for each treatment in a total of five experiments.

'The degree of expansion in this group varied between 0 and +3 , but the majority $(>70 \%)$ was assessed as +2 .

or EGF, to determine whether cumulus-free germinal vesiclestage oocytes could promote FSH-, dbcAMP- or EGF-induced cumulus expansion. As shown in Table 5, FSH, dbcAMP and EGF all stimulated cumulus expansion of the oocytectomized complexes cocultured with denuded oocytes. The degree of expansion of the oocytectomized complexes in oocyte-conditioned medium was similar to that of intact complexes. Expansion of oocytectomized complexes did not occur in control drops of unconditioned medium with any stimuli, or in conditioned medium in the absence of stimuli (Table 5).

Cumulus-free mouse, rat and pig oocytes were cocultured with intact and oocytectomized mouse and rat complexes to determine whether pig oocytes secrete a factor(s) that could affect the oocyte-dependent cumulus expansion of complexes from rats and mice. Rat complexes were preincubated for $5 \mathrm{~h}$ before treatment as described above. FSH stimulated cumulus expansion by all oocytectomized complexes cocultured with denuded oocytes (Table 3). Rat and mouse oocytectomized complexes cocultured with pig oocytes underwent FSH-induced expansion to degrees comparable to those in conspecific cocultures. For each culture condition, the degree of expansion of oocytectomized complexes was similar to that of the corresponding intact complexes.

\section{Preliminary characterization of the enabling factor}

The observation that mouse oocytectomized complexes expand in pig oocyte-conditioned media in response to FSH was used and the biochemical nature of the pig enabling factor was investigated by inactivating any proteins secreted by the oocyte. Treatment of pig-oocyte conditioned media with proteinase $\mathrm{K}$ for $7 \mathrm{~h}$, or by heating at $65^{\circ} \mathrm{C}$ for $30 \mathrm{~min}$ depleted the media of its ability to enable expansion of mouse oocytectomized complexes in the presence of FSH ( 0 expansion). Oocytectomized complexes in untreated oocyte-conditioned media, or in media to which PMSF had been added were able to undergo expansion to +3 levels in response to FSH.

\section{Discussion}

The experiments reported here demonstrate that mouse, rat and pig oocytes all secrete a cumulus expansion-enabling factor(s) that allows the cumulus cells to undergo expansion in response to FSH or EGF. Whereas the expansion of mouse and rat cumulus cells requires the presence of this factor, the expansion of pig complexes in vitro does not depend upon an oocyte-secreted enabling factor. These results were obtained in experiments that demonstrated that microsurgical removal of the oocyte impairs the ability of mouse and rat oocyte-cumulus cell complexes to undergo expansion in response to FSH or dbcAMP. EGF, which stimulates cumulus expansion of intact complexes by a mechanism that, at least initially, is different from $\mathrm{FSH}$, also failed to stimulate cumulus expansion after oocytectomy. When oocytectomized rat complexes were cultured in oocyte-conditioned medium, the cumulus cells underwent expansion after stimulation with FSH, dbcAMP or EGF to the same extent as in intact complexes. In contrast, expansion of pig oocyte-cumulus complexes was not affected by oocytectomy. Medium conditioned by pig oocytes, however, enabled the expansion of rat and mouse oocytectomized complexes in response to FSH.

Expansion of the mouse cumulus oophorus in vitro was found to be dependent upon regulation of hyaluronic acid synthesis by the oocyte (Buccione et al., 1990; Salustri et al., 1990). In the present study, cumulus cells in the expanded complexes from rat, mouse and pig were dispersed in the presence of Streptomyces hyaluronidase. The sensitivity of all expanded complexes to this highly specific hyaluronidase indicates that hyaluronic acid is a component of the expanded complexes of all three species.

In initial experiments, oocytectomy of rat oocyte-cumulus complexes resulted in a somewhat variable response to FSH stimulation. By allowing a period before FSH stimulation, a more consistent, and oocyte-dependent, result was obtained 
Table 3. Expansion of intact and oocytectomized complexes cultured in unconditioned medium or medium conditioned by oocytes of the same or other species

\begin{tabular}{|c|c|c|c|c|c|}
\hline & & \multicolumn{4}{|c|}{ Degree of expansion } \\
\hline \multicolumn{2}{|c|}{ Culture conditions $^{a}$} & \multicolumn{2}{|c|}{ Mouse $^{b}$} & \multicolumn{2}{|r|}{$\operatorname{Rat}^{\mathrm{c}}$} \\
\hline Conditioned by & $\mathrm{FSH}$ & Intact & Oocytectomized & Intact & Oocytectomized \\
\hline- & - & 0 & 0 & 0 & 0 \\
\hline- & + & +3 to +4 & 0 & +3 to +4 & 0 to +1 \\
\hline Mouse oocytes & - & 0 to +1 & 0 & 0 & 0 \\
\hline Mouse oocytes & + & +4 & +3 to +4 & +3 to +4 & +3 \\
\hline Rat oocytes & - & 0 to +1 & 0 & 0 & 0 \\
\hline Rat oocytes & + & +4 & +3 to +4 & +3 to +4 & +3 \\
\hline Pig oocytes & - & 0 & 0 & 0 & 0 \\
\hline Pig oocytes & + & +4 & +3 & +3 to +4 & +3 \\
\hline
\end{tabular}

${ }^{2}$ Conditioned media were prepared by culturing 50 denuded germinal vesicle-stage oocytes in $25 \mu \mathrm{l}$ of medium for $24 \mathrm{~h}$ before addition of intact or oocytectomized complexes. FSH was added at a concentration of $1 \mu \mathrm{g} \mathrm{ml}^{-1}$. ${ }^{\mathrm{b}} 60$ mouse complexes were assessed for each treatment in a total of three experiments.

' 60 to 75 rat complexes were assessed for each treatment in three (mouse and rat oocyte-conditioned media) or five (rat and pig oocyte-conditioned media) experiments. Rat complexes were incubated for $5 \mathrm{~h}$ before treatment. Mouse complexes had no incubation period before treatment.

Table 4. Effect of a delay between oocytectomy and FSH stimulation on the expansion of rat and pig cumulus complexes

\begin{tabular}{|c|c|c|c|c|}
\hline \multirow{3}{*}{$\begin{array}{l}\text { Delay }^{\mathrm{a}} \\
\text { (h) }\end{array}$} & \multicolumn{4}{|c|}{ Degree of expansion } \\
\hline & \multicolumn{2}{|r|}{ Rat $^{\mathrm{b}}$} & \multicolumn{2}{|r|}{$\mathrm{Pig}^{\mathrm{c}}$} \\
\hline & Intact & Oocytectomized & Intact & Oocytectomized \\
\hline 0 & +3 to +4 & +2 to +3 & +4 & +4 \\
\hline I & +3 to +4 & +1 to +3 & - & - \\
\hline 2 & +3 to +4 & 0 to +2 & - & - \\
\hline 4 & +3 to +4 & 0 to +1 & +4 & +4 \\
\hline 8 & +3 & 0 & +4 & +4 \\
\hline 24 & +3 & 0 & +4 & +4 \\
\hline 32 & - & - & +4 & +4 \\
\hline 48 & - & - & +3 & +3 \\
\hline
\end{tabular}

-: not performed.

'For oocytectomized complexes, the delay is the period of culture between the time of oocytectomy and the time when FSH was added to the cultures. Intact complexes were cultured for an equivalent period before FSH stimulation. FSH was added at a concentration of $1 \mu \mathrm{g} \mathrm{ml}^{-1}$.

${ }^{b_{5}} 5$ rat complexes were assessed for each treatment in a total of three experiments.

'60 pig complexes were assessed for each treatment in a total of five experiments.

with a 5-6h preincubation for rat oocytectomized complexes. The need for a delay before rat cumulus cells demonstrated a dependence on the oocyte-secreted factor suggests at least two differences between mouse and rat oocyte-derived factors in their ability to enable cumulus expansion in response to FSH. Rat cumulus cells may have a prolonged responsiveness to
Table 5. Effect of various stimuli on the expansion of intact and oocytectomized complexes cultured in unconditioned or oocyte-conditioned medium

\begin{tabular}{|c|c|c|c|}
\hline \multirow{2}{*}{$\begin{array}{l}\text { Culture } \\
\text { conditions }\end{array}$} & \multirow{2}{*}{$\begin{array}{l}\text { Type of } \\
\text { complex }\end{array}$} & \multicolumn{2}{|c|}{ Degree of expansion } \\
\hline & & $\operatorname{Rat}^{\mathrm{a}}$ & $\mathrm{Pig}^{\mathrm{b}}$ \\
\hline \multirow[t]{2}{*}{ Control } & Intact & 0 & 0 \\
\hline & Oocytectomized & 0 & 0 \\
\hline \multirow[t]{2}{*}{$\mathrm{FSH}\left(1 \mu \mathrm{g} \mathrm{ml}^{-1}\right)$} & Intact & +3 to +4 & +4 \\
\hline & Oocytectomized & 0 & +4 \\
\hline \multirow{2}{*}{$\begin{array}{l}\mathrm{dbcAMP} \\
\quad\left(2 \mathrm{mmol} \mathrm{I}^{-\mathrm{I}}\right)\end{array}$} & Intact & +3 to +4 & +4 \\
\hline & Oocytectomized & 0 & +4 \\
\hline \multirow[t]{2}{*}{$\operatorname{EGF}^{c}\left(2 \mathrm{ng} \mathrm{ml}^{-1}\right)$} & Intact & +3 to +4 & +4 \\
\hline & Oocytectomized & 0 & +4 \\
\hline \multirow[t]{2}{*}{ Coculture $^{\mathrm{d}}$} & Intact & 0 & - \\
\hline & Oocytectomized & 0 & - \\
\hline \multirow[t]{2}{*}{ Coculture + FSH } & Intact & +4 & - \\
\hline & Oocytectomized & +3 & - \\
\hline \multirow{2}{*}{$\begin{array}{c}\text { Coculture + } \\
\text { dbcAMP }\end{array}$} & Intact & +4 & - \\
\hline & Oocytectomized & +3 to +4 & - \\
\hline \multirow[t]{2}{*}{ Coculture + EGF } & Intact & +4 & - \\
\hline & Oocytectomized & +3 to +4 & - \\
\hline
\end{tabular}

a95 rat complexes were assessed for each treatment in a total of seven experiments. Complexes were incubated for $5-6 \mathrm{~h}$ before treatment.

${ }^{b} 60$ pig complexes were assessed for each treatment in a total of five experiments. Complexes were incubated for $24 \mathrm{~h}$ before treatment. 'EGF; epidermal growth factor.

${ }^{d}$ Cocultures were prepared by culturing 50 denuded rat germinal vesicle-stage oocytes in $25 \mu \mathrm{l}$ medium for $24 \mathrm{~h}$. Intact or oocytectomized complexes were then added with or without FSH, dbcAMP or EGF. Rat complexes were incubated for $5-6 \mathrm{~h}$ before adding them to the oocyte-conditioned medium. Since pig complexes expanded fully even after oocytectomy, it was unnecessary to use these complexes in coculture experiments. 
FSH after oocytectomy if the rat oocyte-secreted factor has a longer half-life within the complex than does the mouse enabling factor. Since cumulus expansion-enabling factor is secreted constitutively by the oocyte (Vanderhyden et al., 1990), an alternative explanation may be that rat cumulus cells require a longer period after oocytectomy to lose the biological effects induced by stimulation before oocytectomy. Despite the need for a delay of 5-6h before FSH stimulation, these experiments have shown that the expansion of rat cumulus cells, like mouse cumulus cells, is dependent upon a factor secreted by the oocyte.

In contrast to the rat, preincubations of up to $48 \mathrm{~h}$ were ineffective in demonstrating a dependence of pig cumulus cell expansion on the oocyte. Procházka et al. (1991) demonstrated the lack of effect of oocytectomy on the expansion of pig complexes in response to FSH and suggested that pig oocytes do not secrete a cumulus expansion-enabling factor. The experiments presented here, however, demonstrate that pig oocytes do secrete a factor that enables the expansion of mouse and rat oocytectomized complexes. It appears that the function of this factor in promoting cumulus expansion is different in rodent and pig oocyte-cumulus cell complexes, and this difference may be simply temporal. Previous experiments have determined that, in mice, only meiotically-competent oocytes can secrete the cumulus expansion-enabling factor (Vanderhyden et al., 1990). As the acquisition of meiotic competence and differentiation of granulosa cells into functional (i.e. able to expand) cumulus cells normally occurs at the same time, perhaps during differentiation, the pig enabling factor induces a permanent change in the cumulus cells that enables them to undergo expansion whenever the appropriate hormonal stimulation occurs. In contrast, the secretion of enabling factor in rodent complexes may not induce permanent changes during differentiation, and, therefore, they require the immediate presence of the enabling factor at the time of exposure to FSH. It is also conceivable that the cumulus expansion-enabling factor secreted by pig oocytes is not necessary for the expansion of pig complexes, but plays some other role in the development or function of cumulus cells.

Since the mouse and rat oocyte-cumulus complexes used in these experiments were obtained from PMSG-primed animals, whereas the pig complexes were collected from unprimed animals, it is possible that a difference in physiological/hormonal environment is responsible for the species differences noted here. However, in a previous study (Vanderhyden et al., 1990) using primed and unprimed mice, oocytes isolated from the early antral follicles of unprimed 16-day-old mice could secrete the cumulus expansion-enabling factor and, further, the cumulus cells from these mice could expand if cultured in the presence of sufficient enabling factor. Similar results have since been obtained using rat complexes from unprimed animals (B. C. Vanderhyden, unpublished observations). In addition, Procházka et al. (1991) demonstrated the lack of effect of oocytectomy on the expansion of pig complexes obtained from PMSG-primed animals. These observations indicate that priming has no apparent effect on the ability of oocytes to secrete the cumulus expansion-enabling factor, nor on the ability of cumulus cells to respond to this factor.

Investigation of the biochemical nature of the oocyte-secreted cumulus expansion-enabling factor may prove to be somewhat difficult. Denuded oocytes cannot be easily obtained, especially in the pig, in the numbers needed to condition sufficient media for biochemical analysis. This problem is compounded by the fact that the enabling factor is very unstable, and loses activity when stored under any of the conditions tested to date (J. J. Eppig and B. C. Vanderhyden, unpublished observations). Preliminary characterization of the mouse enabling factor by Eppig et al. (in press) has revealed that the factor is heat labile $\left(65^{\circ} \mathrm{C}\right.$ for $15 \mathrm{~min}$ ), and proteinase $\mathrm{K}$ sensitive, and its activity is retained in the fraction with molecular mass $>100 \mathrm{kDa}$ during fractionation. In the present study, similar experiments using media conditioned by pig oocytes have demonstrated that the pig oocyte-secreted factor is also heat labile and proteinase $\mathrm{K}$ sensitive. Because large quantities of oocytes are necessary to condition the medium, biochemical analysis is far more feasible with rodents, where large numbers of oocytes can be grown in vitro (Eppig et al., in press). Further characterization of the enabling factor will allow us to investigate the role of this factor in porcine follicle development.

Contact of granulosa cells with a collagen-containing basal lamina affects cell structure, synthesis and organization of cytoskeletal components, and the development of functional LH receptors (Amsterdam et al, 1989). In comparison, the differentiation of mouse cumulus cells, and their ability to undergo cumulus expansion depend upon contact with the oocyte or oocyte-secreted factors (Buccione et al., 1990; Vanderhyden et al., 1990). These observations suggest that the oocyte and the basal lamina play critical roles in the differentiation and function of subpopulations of granulosa cells. It is not known which of these two substrates has the dominant effect on the differentiation and function of the piece of mural granulosa that connects the mural granulosa cells to the cumulus granulosa cells. However, the clear delineation between granulosa cells that can expand and those that cannot suggests that the boundaries indicating the limit of influence of the substrates are very well defined. If oocyte-secreted factors promote the ability of granulosa cells to undergo expansion, and if the concentration of these factors decreases in a gradient away from the oocyte, then perhaps a minimum concentration of this factor is necessary to induce the responsiveness of the cumulus cells to FSH.

In mice, the granulosa cells comprising the stalk between the oocyte-cumulus cell complex and the collagen membrane upon which the complex was grown in vitro do not undergo expansion in response to FSH, suggesting that the granulosa cells of the stalk resemble mural granulosa cells (Vanderhyden et al., 1990). In contrast, the experiments reported here and in a previous study (Procházka et al., 1991) demonstrated that, in the pig, pieces of membrana granulosa could undergo expansion even when separated from the oocyte-cumulus cell complex, suggesting that these cells resemble cumulus granulosa cells. These observations indicate that there may be differences between species in the function of the granulosa cells that are most closely connected to the cumulus cells or that the range of oocyte-secreted factors that enable cumulus expansion may extend further in pig follicles than in mouse or rat follicles. However, the mouse oocyte-granulosa cell complexes grown in vitro were supported on a stalk of granulosa cells that adhered directly to a collagen-coated membrane as opposed to the normal mural granulosa cells. This deviation from the normal cellcell associations in favour of cell-substrate interactions may 
have directed the stalk of granulosa cells along a path of differentiation similar to mural granulosa cells.

These experiments have shown that expansion of mouse and rat cumulus cells depends upon the presence of an oocytesecreted enabling factor. The expansion of pig complexes in vitro appears to be independent of the oocyte or any oocytesecreted factors, suggesting that the regulation of cumulus expansion in pig complexes is different from that in rodents. Although the magnitude of the differences between these species in the regulation of cumulus expansion will only be known when the function of the porcine enabling factor has been identified, the observations that rat, mouse and pig oocytes all secrete a cumulus expansion-enabling factor and that complexes from all these species undergo expansion in response to FSH and EGF suggests that there are important cross-species similarities in the factors that regulate cumulus expansion. These similarities suggest that there may be only subtle (for example, temporal) species-dependent differences in the specific function of the cumulus expansion-enabling factor or the responsiveness to gonadotrophins that it induces in cumulus cells.

This research was supported by the National Cancer Institute of Canada. The author thanks J. J. Eppig for his critical review of this manuscript. Thanks also to the National Institute of Diabetes and Digestive and Kidney Disease and the National Hormone and Pituitary Program of the University of Maryland School of Medicine for generously providing the FSH used in these experiments.

\section{References}

Amsterdam A, Koch Y, Lieberman ME and Lindner HR (1975) Distribution of binding sites for human chorionic gonadotropin in the preovulatory follicle of the rat Joumal of Cell Biology $67894-900$

Amsterdam A, Rotmensch S, Furman A, Venter EA and Vlodavasky I (1989) Synergistic effect of human chorionic gonadotropin and extracellular matrix on in vitro differentiation of human granulosa cells: progesterone production and gap junction formation Endocrinology 124 1956-1964

Anderson A and Albertini DF (1976) Gap junctions between the oocyte and companion follicle cells in the mammalian ovary Journal of Cell Biology $\mathbf{7 1}$ 680-686

Ball GD, Wieben ED and Byers AP (1985) DNA, RNA and protein synthesis by porcine oocyte-cumulus cell complexes during expansion Biology of Reproduction 33 739-744

Bortolussi M, Marini G and Reolon ML (1979) A histochemical study of the binding of ${ }^{125}$ I-labelled HCG to the rat ovary throughout the estrous cycle Cell and Tissue Research 197 213-226

Buccione R, Vanderhyden BC, Caron PJ and Eppig JJ (1990) FSH-induced expansion of the mouse cumulus oophorus in vitro is dependent upon a specific factor(s) secreted by the oocyte Developmental Biology 138 16-25
Dekel N and Kraicer PF (1978) Induction in vitro of mucification of rat cumulus oophorus by gonadotropins and adenosine $3^{\prime}, 5^{\prime}$-monophosphate Endocrinology 102 1797-1802

Downs SM, Daniel SAJ and Eppig JJ (1988) Induction of maturation in cumulus cell-enclosed mouse oocytes by follicle-stimulating hormone and epidermal growth factor: evidence for a positive stimulus of somatic cell origin Journal of Experimental Zoology 245 86-96

Eppig JJ (1979a) FSH stimulates hyaluronic acid synthesis by oocyte-cumulus cell complexes from mouse preovulatory follicles Nature 281 483-484

Eppig JJ (1979b) Gonadotropin stimulation of the expansion of cumuli oophori isolated from mice: general conditions for expansion in vitro Journal of Experimental Zoology 208 345-353

Eppig JI, Peters AHFM, Telfer EE and Wigglesworth K Production of cumulus expansion enabling factor by mouse oocytes grown in vitro: preliminary characterization of the factor Molecular Reproduction and Development (in press)

Heller DT and Schultz RM (1980) Ribonucleoside metabolism by mouse oocytes: metabolic cooperativity between fully grown oocytes and cumulus cells Journal of Experimental Zoology 214 355-364

Hillensjo T and Channing CP (1980) Gonadotropin stimulation of steroidogenesis and cellular dispersion in cultured porcine cumuli oophori Gamete Research 3 223-240

Hillensjo T, Magnusson C, Svensson U and Thelander $H$ (1981) Effect of luteinizing hormone and follicle-stimulating hormone on progesterone synthesis by cultured rat cumulus cells Endocrinology 108 1920-1924

Lawrence TS, Dekel N and Beers WH (1980) Binding of human chorionic gonadotropin by rat cumuli oophori and granulosa cells: a comparative study Endocrinology 106 1114-1118

Moor RM, Smith MW and Dawson RMC (1980) Measurement of intercellular coupling between oocytes and cumulus cells using intracellular markers Experimental Cell Research 126 15-29

Procházka R, Nagyová E, Rimkevičová Z, Nagai T, Kikuchi K and Motlík J (1991) Lack of effect of oocytectomy on expansion of the porcine cumulus Joumal of Reproduction and Fertility 93 569-576

Salustri A, Yanagishita M and Hascall VC (1989) Synthesis and accumulation of hyaluronic acid and proteoglycans in the mouse cumulus cell-oocyte complex during follicle-stimulating hormone-induced mucification Journal of Biological Chemistry $26413840-13847$

Salustri A, Yanagishita M and Hascal VC (1990) Mouse oocytes regulate hyaluronic acid synthesis and mucification by FSH-stimulated cumulus cells Developmental Biology 138 26-32

Thibault C (1972) Final stages of mammalian meiotic maturation. In Oogenesis, pp 397-411 Eds JD Biggers and AW Schuetz. University Park Press, Baltimore

Vanderhyden BC, Caron PJ, Buccione R and Eppig JJ (1990) Developmental pattern of the secretion of cumulus expansion-enabling factor by mouse oocytes and the role of oocytes in promoting granulosa cell differentiation Developmental Biology 140 307-317

Vanderhyden BC, Telfer EE and Eppig JJ (1992) Mouse oocytes promote proliferation of granulosa cells from preantral and antral follicles in vitro Biology of Reproduction 46 1196-1204

Zoller LC and Weisz J (1978) Identification of cytochrome P-450, and its distribution in the membrana granulosa of the preovulatory follicle, using quantitative cytochemistry Endocrinology 103 310-313

Zoller LC and Weisz J (1979) A quantitative cytochemical study of glucose-6phosphate dehydrogenase and $\Delta^{5}$-3 $\beta$-hydroxysteroid dehydrogenase activity in the membrana granulosa of the ovulable type of follicle of the rat Histochemistry 62 125-135 